\title{
No Evidence of Short-Term Exchange of Meat for Sex among Chimpanzees
}

\section{Citation}

Gilby, Ian C., M. Emery Thompson, Jonathan D. Ruane, and Richard W. Wrangham. 2010. No evidence of short-term exchange of meat for sex among chimpanzees. Journal of Human Evolution 59(1): 44-53.

\section{Published Version}

doi:10.1016/j.jhevol.2010.02.006

\section{Permanent link}

http://nrs.harvard.edu/urn-3:HUL.InstRepos:5346654

\section{Terms of Use}

This article was downloaded from Harvard University's DASH repository, and is made available under the terms and conditions applicable to Open Access Policy Articles, as set forth at http:// nrs.harvard.edu/urn-3:HUL.InstRepos:dash.current.terms-of-use\#OAP

\section{Share Your Story}

The Harvard community has made this article openly available.

Please share how this access benefits you. Submit a story.

Accessibility 
No evidence of short-term exchange of meat for sex among chimpanzees.

${ }^{1}$ GILBY, IAN C.; ${ }^{2}$ EMERY THOMPSON, M.; ${ }^{3}$ RUANE, JONATHAN D.; ${ }^{1}$ WRANGHAM, RICHARD W.

${ }^{1}$ Department of Human Evolutionary Biology, Harvard University

${ }^{2}$ Department of Anthropology, University of New Mexico

${ }^{3}$ Department of Archaeology, Boston University

Correspondence: I. Gilby, 11 Divinity Ave, Cambridge, MA 02138 USA (TEL: (617)

496-4262; FAX: (617) 496-8041; Email: gilby@,fas.harvard.edu)

Keywords: biological markets, chimpanzee, food sharing, hunting, mate provisioning, meat eating, meat-for-sex, reciprocity, tolerated theft

Running title: Chimpanzee meat sharing 


\begin{abstract}
The meat-for-sex hypothesis posits that male chimpanzees (Pan troglodytes) trade meat with estrous females in exchange for short-term mating access. This notion is widely cited in the anthropological literature and has been used to construct scenarios about human evolution. Here we review the theoretical and empirical basis for the meat-for-sex hypothesis. We argue that chimpanzee behavioral ecology does not favor the evolution of such exchanges because 1) female chimpanzees show low mate selectivity and require little or no material incentive to mate, violating existing models of meat-for-sex exchange; and 2) meat-for-sex exchanges are unlikely to provide reproductive benefits to either partner. We also present new analyses of 28 years of data from two East African chimpanzee study sites (Gombe National Park, Tanzania; Kanyawara, Kibale National Park, Uganda) and discuss the results of previously published studies. In at least three chimpanzee communities, 1) the presence of sexually receptive females did not increase hunting probability; 2) males did not share preferentially with sexually receptive females and 3) sharing with females did not increase a male's short-term mating success. We acknowledge that systematic meat-sharing by male chimpanzees in expectation of or as reward for immediate copulations might be discovered in future studies of chimpanzees. However current data indicate that such exchanges are so rare in studied populations, and are so different in nature from exchanges among humans, that with respect to chimpanzees, sexual bartering in humans should be regarded as a derived trait with no known antecedents in the behavior of wild chimpanzees.
\end{abstract}




\section{Introduction}

In this paper we review published articles and provide new data on the influence of female sexual state on hunting and meat sharing among chimpanzees (Pan troglodytes) to review the 'meat-for-sex' hypothesis. The meat-for-sex hypothesis proposes that male chimpanzees share meat with females in exchange for short-term mating access. Specifically, the meat-for-sex hypothesis states that, “...the hunting performance of chimpanzees may be under sexual selection for capture and/or control of meat as a way to obtain additional copulations from females with estrous swellings in the hunting party” (Stanford, 1996, p. 101). Meat-for-sex exchanges among chimpanzees are often treated as a well-established, species-typical phenomenon (e.g. Radetsky, 1995; Bird, 1999; Hawkes and Bird, 2002; Shlain, 2003; Bunn, 2007; Lovejoy, 2009), and they provide the basis for various speculations about the evolution of human sexual behavior (e.g Lovejoy 2009).

Among humans the trading of meat for sex can be explicit. Siriono wives who are more sexually active with their husbands reportedly get more to eat (Holmberg, 1969, p. 126), while men use meat to obtain extramarital sex (Holmberg, 1969, p. 166). Among the Mehinaku, women are said to, "use their sexuality to secure food and support in exchange for intercourse" (Gregor, 1985, p. 33), and men secretly give fish to their lovers as a symbol of their productivity and sexuality (Gregor, 1985, p. 75). The Kulina practice a public ritual called 'order to get meat' (Pollock, 2002, p. 52) which begins when each woman raps on a man's house at dawn with a stick. If that man hunts successfully that day, she will have sex with him. After the men hunt, women form a semi-circle around 
them, requesting meat while singing erotically provocative songs. Men hurl the meat in a pile, and the women cook and eat it before retiring with the selected partner.

Clear examples of food-for-sex exchanges also occur in many non-primate species, especially insects (Thornhill, 1984; Noë and Hammerstein, 1994; Arnqvist and Nilsson, 2000; Fedorka and Mousseau, 2002). However the claim that chimpanzees trade meat for copulations is more important for human evolution because it raises the question of whether human meat-for-sex exchanges can be traced to a pre-human ancestry. In this paper we review the full theoretical and empirical base underlying the meat-for-sex hypothesis in chimpanzees and present new data from Gombe National Park, Tanzania and Kibale National Park, Uganda. We find that the behavioral observations which provided the initial impulse for the meat-for-sex hypothesis have never been replicated and can be explained by alternative mechanisms. In four study populations (Gombe, Kanyawara, Ngogo, Taï) controlled examinations of multiple predictions of the hypothesis find no evidence that chimpanzees systematically exchange meat for copulations on a short-term basis.

Although short-term exchanges of meat for sex are thus contra-indicated, Gomes and Boesch (2009) reported that in Taï there was a long-term correlation across malefemale dyads between meat-sharing and copulations. Specifically, in dyads within which at least one episode of meat-sharing occurred, copulations were more likely. Gomes and Boesch (2009) interpreted this result as indicating that meat was exchanged for sex. However, despite careful analysis they failed to find any evidence that meat-sharing was correlated with copulations over the short-term. Their result is therefore mysterious, since 
it implies that the motivation of estrous females to copulate was not affected in the short term by receiving meat, whereas it was affected in the long term. In this paper our data do not address the possibility that chimpanzees exchange meat for sex over a period of days, weeks or months. We are concerned only with the question of whether they perform these exchanges within the immediate context of a meat-eating group.

\section{Chimpanzee natural history \& meat sharing}

Chimpanzees typically live in communities of approximately 40-50 individuals, although some communities can reach $\sim 150$ (e.g. Ngogo, Kibale National Park: Mitani and Watts, 1999). Within a community, fission-fusion grouping generates 'parties' of varying size, composition and temporal stability (Nishida, 1968; Wrangham and Smuts, 1980; Goodall, 1986). Thus, while male and female members of a community maintain long-term social relationships, the strength of these relationships varies as does the frequency of contact between any two individuals (e.g. Gilby and Wrangham, 2008). Reproductive rates are very slow, with a mean female inter-birth interval of 5-7 years (data from 6 sites summarized by Emery Thompson et al., 2007a). Cycling females exhibit a large anogenital estrous swelling for approximately 10-12 days per 35-day cycle (Wallis, 1997). With very few exceptions, females mate only when they are maximally swollen (Goodall, 1986; Wallis, 1997). We refer to females with a maximal sexual swelling as

11/15/09 5:18 PM

Note that actually there are many ways of referring to maximally swollen females (estrous, swollen, sexually receptive, females with maximal swellings ...). It might be worth going through and trying to be a bit more systematic, especially since we stress the importance of distinguishing maximal swellings from others. 'estrous' females. Females usually experience multiple cycles and mate with many males before each conception (Tutin, 1979; Wrangham, 2002; Deschner and Boesch, 2007; Emery Thompson and Wrangham, 2008a; Watts, 2007). 
Chimpanzees primarily eat ripe fruit, leaves \& other plant materials. However, they also prey upon small- and medium-sized vertebrates. Where available, the most common prey is the red colobus monkey (Procolobus spp.) (Uehara, 1997). Meat consumption varies considerably across populations. At one extreme, the Ngogo chimpanzees killed and consumed at least 292 prey items during a 34-month study period ( $~ 103$ prey per year, Watts and Mitani, 2002b). At the other extreme, chimpanzees in the Budongo Forest, Uganda were observed to eat meat only 17 times in more than 10 years (Newton-Fisher et al., 2002; Reynolds, 2005). Even where hunting occurs with some frequency, some individuals rarely if ever gain access to meat (Gombe: Goodall, 1986; Taï National Park, Côte d'Ivoire: Boesch and Boesch-Achermann, 2000; Ngogo: Mitani and Watts, 1999). These observations suggest that meat is not an essential component of chimpanzee diet (Boesch and Boesch-Achermann, 2000). However, prey animals offer a concentrated source of protein, fat and micronutrients (Teleki, 1973; Takahata et al., 1984; Goodall, 1986; Boesch, 1994; Stanford, 1996; Mitani and Watts, 2001; Milton, 2003a; b; Tennie et al., 2009) and are clearly a highly preferred food item for males and females alike.

While females occasionally hunt (Goodall, 1986; Boesch, 1994; Watts and Mitani, 2002b), males are responsible for most kills and readily seize fresh prey caught by others, and are therefore most often in a position to share meat. When a male obtains prey, several adult male and female chimpanzees typically surround the possessor, each begging for a piece of the carcass (Teleki, 1973; Wrangham, 1975; Takahata et al., 1984; Goodall, 1986; Boesch and Boesch-Achermann, 2000; Gilby, 2006). Begging behavior 
includes pulling on the carcass, attempting to co-feed, and reaching toward the possessor's mouth (Teleki, 1973; Goodall, 1986; Gilby, 2006). Possessors often attempt to reduce such harassment by sneaking away, sitting on terminal branches and/or physically retaliating against particularly persistent beggars (Wrangham, 1975; Goodall, 1986; Gilby, 2004).

Despite these attempts to avoid beggars, meat possessors in Gombe and Ngogo share in approximately 50\% of all begging bouts (Mitani and Watts, 2001; Watts and Mitani, 2002a; Gilby, 2006). Most often, possessors share 'passively' by allowing an individual to take pieces or feed from the carcass (Boesch and Boesch, 1989; Gilby, 2006). However, sharing may also be 'active', i.e. the possessor facilitates transfer by purposefully dividing the carcass, handing a piece to a beggar, or depositing a mouthful of meat into a waiting hand (Teleki, 1973; Goodall, 1986; Boesch and Boesch, 1989; Gilby, 2006). At Gombe, approximately $20 \%$ of sharing events are active (Gilby, unpublished data).

\section{Study sites and data collection}

Our new data analysis comes from Gombe and Kanyawara (Kibale National Park), two of the longest continuously studied free-ranging chimpanzee communities. Systematic data collection has been ongoing since 1974 at Gombe (Goodall, 1986) and 1987 at Kanyawara (Wrangham et al., 1992). For the present study, we analyzed data collected from 1995 to 2005 at Gombe, and from 1990 to 2006 at Kanyawara. During these study periods, teams of observers, which included local field assistants and experienced 
scientists, followed chimpanzees from dawn until dusk on most days at both sites. At Kanyawara, the team followed and recorded data on a party of chimpanzees, and at Gombe, they followed a focal adult. At both sites, one observer recorded party composition, feeding behavior, and location at 15-minute intervals. Another observer made detailed notes ad libitum of all social behavior, including aggression, mating and hunting. After a successful hunt, the observers wrote detailed accounts of all meat-eating, including the identity of meat possessors and beggars and the occurrence of sharing and mating. At Gombe, the observers concentrated their sampling efforts on the focal individual.

Confidence in the accuracy of these data comes from the presence of several observers dedicated to obtaining detailed descriptions of all behavior through immediate collaborative discussion. At Kanyawara, observers average over $95 \%$ in inter-observer reliability tests (Kibale Chimpanzee Project, unpublished data). For more detail on longterm data collection at Kanyawara, see Gilby et al. (2008), Emery Thompson et al. (2007b), and Muller et al. (2007). Data collection at Gombe was described by Goodall (1986), Williams et al. (2002) and Gilby et al. (2006).

In this study, we analyzed data from 260 successful hunts that occurred during 11 years at Gombe, and 126 successful hunts that occurred during 17 years at Kanyawara. For simplicity, we provide the specific details, including sample sizes and analytical criteria when reporting each result.

In addition to long-term data, we also used targeted data on meat sharing collected at Gombe by I. Gilby over 12 months of field work during peak hunting periods between 
1999 and 2002. Gilby videotaped 65 meat-eating bouts (defined as the total time an individual possessed meat following a successful hunt) by five focal males, and subsequently extracted detailed begging, sharing and mating data. Further details are described by Gilby (2006). In the present article, we provide new analyses of these data (the "Gilby dataset" hereafter). We used SAS 9.1 (SAS Institute, Cary, North Carolina) for all analyses, and set statistical significance at $\alpha=0.05$.

We take the following approach. First, we discuss two critical assumptions that must be satisfied for short-term meat-for-sex exchanges to evolve. We argue that as a consequence of certain fundamental aspects of chimpanzee behavioral ecology, these assumptions are unrealistic for this species. Therefore, we conclude that chimpanzees should not be expected to trade meat-for-sex. We then refer to published data and use our own new analyses to test four predictions generated by the meat-for-sex hypothesis.

\section{Assumptions of the meat-for-sex hypothesis}

The meat-for-sex hypothesis hinges upon the assumptions that 1) females need incentive to overcome their reluctance to mate, and 2) the change in female behavior following meat transfer can enhance the reproductive success of the male donor. While previous studies of meat sharing among chimpanzees are rarely this explicit, these assumptions are fundamental to the evolutionary hypotheses that are most often invoked to explain such exchanges. Reciprocal altruism theory (Trivers, 1971) posits that individuals take turns engaging in costly acts that benefit the other, resulting in a net benefit for both participants over time. Therefore, if we view meat-for-sex as a reciprocal exchange, we 
must assume that for the female, mating with certain males incurs a greater cost than withholding sex, but that this cost is offset by the benefits of obtaining meat. Biological markets theory (Noë et al., 1991; Noë \& Hammerstein, 1995) is based upon similar principles, noting specifically that partners exchange commodities over which each has differential control. However, as we demonstrate below, both theory and available empirical evidence suggest that under most circumstances female chimpanzees pay low costs by mating and even gain benefits through promiscuity. Furthermore, a number of characteristics of the mating system of chimpanzees make it unlikely that meat-for-sex exchanges would significantly alter male or female reproductive success. This obviates the evolutionary significance of meat sharing as a mating strategy for chimpanzees, even if it occasionally occurs. Thus, with specific reference to the evolution of mating markets and "nuptial gifts", we argue below that current models entail assumptions and predictions that are unrealistic for chimpanzees.

We begin by challenging the notion that female chimpanzees should be reluctant to mate in general. Females in species that form multi-male, multi-female social groups can benefit in several ways by mating promiscuously. Mating with many males may 1) confuse paternity, and thus discourage infanticide (Hrdy, 1979; van Schaik et al., 2000); 2) promote sperm competition, thereby increasing the chances of acquiring high quality genes (Clutton-Brock and Harvey, 1976); and 3) ensure fertilization (Milton, 1985; Small, 1988). Indeed, in chimpanzees, a single conception typically entails hundreds of copulations with most males in the community (Tutin, 1979; Hasegawa and HiraiwaHasegawa, 1990; Wrangham 2002). Females sometimes mate extensively during 
pregnancy (Wallis, 1982, Kibale Chimpanzee Project, unpublished data). Furthermore, mating patterns indicate that females engage in a high number of copulations in order to mate with more males rather than to mate more frequently with a particular male (Wrangham, 2002; Watts, 2007).

Consistent with the argument that mating is a low-cost activity for females (thereby violating assumption $\# 1$ ), rates of female resistance to male copulation solicitations are low. Goodall (1986) notes that at Gombe, females failed to approach for copulation (within one minute) after only 61 (4\%) of 1475 male solicitations. Forty-one $(67 \%)$ of these refusals involved a single sterile female or the male's maternal sister. The pattern at Kanyawara is similar. We identified all male copulation attempts (defined as copulatory mounts or near-mounts following male approach or solicitation) in the longterm data between 1996 and 2006. During this period, only 55 (3\%) of 1894 male copulation attempts failed due to female resistance (rather than male interference), usually because the female ran away screaming or was aggressive to the male. Even in these rare events, it was often noted that a female fled a copulation in response to threats from other males, rather than in direct resistance to her partner. At Taï resistance has been defined more broadly as a female ignoring or moving away from the male in her first response to his solicitation, regardless of whether she subsequently mated him. Females were resistant to only 265 of 938 (28\%) male copulation attempts (Stumpf and Boesch, 2006; c.f. $8 \%$, Boesch and Boesch-Achermann, 2000). This was only marginally higher than the $21 \%$ of female solicitations that were resisted by males (Stumpf \& Boesch, 2006). 
Thus, neither theoretical expectations nor empirical evidence support the assumption that female chimpanzees are generally reluctant to mate. However, it has been suggested that females display subtle preferences for certain males when conception probability is highest (Taï: Stumpf and Boesch, 2005; Kanyawara: Pieta, 2008; Mahale: Matsumoto-Oda, 1998), raising the possibility that meat sharing could skew these preferences. Under existing models of mating markets (e.g., Noë and Hammerstein, 1994; 1995; Gwynne, 2008), two additional conditions must be met for this to be a feasible argument for explaining the evolution of meat sharing in chimpanzees. First, female mate selectivity must be an important predictor of male reproductive success, as in insects that provide "nuptial gifts" (Gwynne, 2008). In other words, female choice must influence male mating outcomes. If females cannot achieve their mating preferences, then meat will not affect the outcome of any conflict of interest. Second, given the high cost of reproduction for females, preference for a male that offers meat should benefit the female in one of three ways: (a) the energetic benefit should help subsidize the costs of reproduction; (b) the willingness to share meat should be an indication of a male's future investment in offspring care; or (c) the ability of the male to acquire meat should be indicative of his genetic quality. However, male chimpanzees neither provision infants nor provide obvious forms of paternal care. As noted previously, any caloric benefits gained from shared meat seem to be small, although meat may provide micronutrients that could positively affect a female's reproductive success (Tennie et al., 2009). It remains possible that meat sharing provides an advertisement of male fitness. However, 
as we argue below, the preponderance of various male competitive strategies suggest a limited role for female selectivity in determining male reproductive success.

Three alternative male strategies, which are strongly supported as determinants of reproductive success, suggest that female mate choice plays a minor role in chimpanzee communities, although this may vary across populations. First, as in many multi-male species, male chimpanzees fight intensely over mating opportunities and powerful males often use possessive tactics to monopolize or control access to an estrous female (Tutin, 1979). Males initiate the majority of copulations (Gombe: Goodall, 1986; Kanyawara: Emery Thompson, 2008b; Taï: Stumpf and Boesch 2006), and the intensity of male mating effort and competition increases when females are most likely to conceive (Emery Thompson, 2008b). Thus, high-ranking males achieve the highest mating success, particularly with the most attractive or fecund females (Mahale: Nishida, 1997; Budongo: Newton-Fisher, 2004; Kanyawara: Muller et al., 2006; Duffy et al., 2007). Additionally, paternity results from Gombe (Constable et al., 2001; Wroblewski et al., 2009), Taï (Boesch et al., 2006), Mahale (Inoue et al., 2008), and Budongo (Newton-Fisher et al., in review) indicate that high rank and the use of competitive mating strategies is a strong, although not perfect, predictor of male reproductive success in chimpanzees.

Second, while it is extremely rare for male chimpanzees to force a female to copulate (0.001\% of matings at Taï, (Stumpf and Boesch, 2006); 0.002\% at Gombe, (Goodall, 1986), males, who are approximately 25\% heavier than females (Pusey et al., 2005), frequently use aggression against females (Muller, 2002). At Kanyawara, such aggression increased in the peri-ovulatory period (POP), when conception probability 
was highest, and a male's aggression towards a particular female predicted his relative mating success with that female (Muller et al., 2007). Similar patterns occur at Gombe, where Goodall (1986) notes that, 'By attacking his female...[a] possessive male not only stops her from mating with his rival, but also delivers a warning that she should avoid the sexual advances of other males'. In fact, at Kanyawara, conditioning aggression by highranking males is sufficient to explain inter-individual and temporal variation in female solicitation patterns (Muller et al., 2009, in review) that are often used as measures of preference (Stumpf and Boesch, 2005; 2006; Pieta, 2008). It is feasible, however, that the impact of coercion on the expression of female preferences varies in chimpanzees, as suggested by West African chimpanzee (P.t. verus) females at Taï, who are reported to exert choice more effectively (Stumpf and Boesch, 2005; 2006).

In sum, based on the available evidence, it is likely that female mate preferences have a weak overall influence on male reproductive outcomes in chimpanzees in comparison with the forces of male aggressive competition, sexual coercion and sperm competition, suggesting that sharing meat with the occasional reluctant female would do little to increase a male's reproductive success. This conclusion is reinforced by the fact that male meat possessors are usually high-ranking (e.g. Gilby, 2006). These males already hold a significant advantage in securing matings by virtue of aggressive competition with other males and their ability to effectively use mate-guarding and coercive aggression to increase their relative mating success. The competitive success of high-ranking male chimpanzees also suggests high genetic quality, making it likely that 
they are desirable mates regardless of any sharing behavior (Tutin, 1979; Goodall, 1986; Matsumoto-Oda; 1999; Stumpf and Boesch, 2005).

Meat-for-sex exchanges are therefore generally implausible among chimpanzees. By contrast they have obvious potential significance in insects and humans, because females in those species restrict their copulations to one or a few males and obtain large nutritional benefits from substantial portions of meat. Nevertheless, when low- and midranking male chimpanzees do control shareable portions of meat (Goodall, 1986; Gilby, 2006), such as when multiple monkeys are captured, or when high-ranking males have eaten their fill, they could be in a position to trade meat for sex as an alternative strategy to competition. We therefore address the empirical base for meat-for-sex exchanges among chimpanzees.

\section{Predictions of the meat-for-sex hypothesis}

Prediction 1: Males are more likely to hunt when estrous females are available

The only empirical support for the meat-for-sex hypothesis that has reported a statistically significant result is that in Gombe, male chimpanzees were more likely to hunt monkeys when estrous females were present. Using 10 years of long-term data on Gombe chimpanzees, including 729 red colobus encounters and 529 hunts, Stanford et al. (1994) found that upon encountering a troop of red colobus monkeys, parties containing estrous females were more likely to hunt than parties without estrous females, after controlling for party size. Stanford et al. (1994) proposed that this pattern emerged because the potential to trade meat for sex provided an added incentive for hunting. 
Two features of the original analysis suggest that this result needs to be reexamined. First, Stanford et al. (1994) classified females as 'estrous' even when their ano-genital regions were only partially (3/4) swollen. Since adult females very rarely mate unless they are fully swollen (Goodall, 1986; Wallis, 1997), partially swollen females should not be classified as potential short-term mating partners. Second, in the long-term Gombe records that Stanford et al. (1994) used for their study, the term 'hunt' included instances in which males ran along the ground beneath colobus monkeys but did not climb toward them (Gilby, pers. obs.). Thus the 'hunts' in Stanford et al.'s (1994) dataset were vulnerable to including instances when chimpanzees showed interest in pursuing prey, but did not actually do so.

Gilby et al. (2006) therefore analyzed 25 years of long-term data from Gombe, including the period studied by Stanford et al. (1994)). Using the conventional definition of 'hunt' (climbing in pursuit of prey, cf. Boesch and Boesch, 1989; Mitani and Watts, 1999), Gilby et al. (2006) found that at a given party size, a hunt was significantly less likely to occur if maximally-swollen estrous females were present, opposite to Stanford et al's (1994) result (Figure 1). Thus the presence of estrous females could in theory promote male interest in hunting, but it reduces the probability of hunting.

The same analysis has been conducted at two other sites. At Kanyawara Gilby et al. (2008) found a similar trend, suggesting that hunting was less likely when fully estrous females were present $(\mathrm{P}=0.08)(610$ encounters, 99 hunts). By contrast, Mitani and Watts (2001) showed that the presence of swollen females had no effect on male hunting probability at Ngogo (164 encounters, 61 hunts). 
Therefore, at the three sites where Prediction 1 has been tested with data on hunting behavior in the presence of fully estrous females, it has been rejected (Table 1). Gilby et al. (2006) suggested that males encountering potential prey may be forced to choose between hunting and mating. Males frequently guard estrous females from mating with other males. Solo mate-guarding becomes less likely to succeed in a large party (Watts, 1998), and male chimpanzees cannot simultaneously mate-guard and hunt. Therefore even if males are more interested in hunting when swollen females are present (Stanford et al. 1994), they might forgo the opportunity to hunt if doing so would compromise their ability to monopolize a sexually receptive female.

Prediction 2: Males share preferentially with estrous females.

Even though sexual interest is not known to drive hunting decisions at Gombe, Ngogo and Kanyawara, it could still influence the motivation to share once meat is acquired. If meat were being exchanged for sex, one would expect preferential sharing with estrous females. Teleki's (1973) study of meat eating among the Gombe chimpanzees is frequently cited as providing support for this prediction because Teleki stated that estrous females that 'took and requested' meat from male meat possessors were more likely to obtain meat $(91 / 132$ 'interactions' $=69 \%$ success $)$ than anestrous females $(42 / 104=$ $40 \%$ success). Critically, however, neither statistical tests nor data on individuals were reported (Teleki, 1973, pg. 162-3). Furthermore, Teleki’s (1973) report does not differentiate between begging ('requesting') and sharing ('taking'), and it is therefore 
unclear whether swollen females were actually more likely to obtain meat than nonswollen females.

At Taï, there was a tendency for males to share meat more frequently with estrous females than with anestrous females after controlling for their proportional representation in the party $(\mathrm{P}=0.06, \mathrm{~N}=5$ males, Gomes and Boesch, 2009), and at Ngogo, males shared with swollen females more often than expected by chance (Watts and Mitani, 2002a). However, neither of these analyses reported the relative frequency with which females approached male meat possessors, nor did they take differences in begging behavior into account. Plausibly therefore, swollen females were more likely to obtain meat because they were more likely to approach meat possessors (Goodall, 1986). Indeed, ‘...estrous females stay closer to adult males during predation and are more persistent in their efforts to obtain meat' (Teleki, $1973 \mathrm{pg}$ 163). The strength of a female's interest in obtaining meat is thus a vital component of any test of the prediction that males preferentially share with estrous females.

To illustrate this important point, when Watts and Mitani (2002a) analysed their Ngogo data using each begging bout as the unit of analysis, estrous and anestrous females obtained meat at equal rates. Specifically, estrous female beggars obtained meat in $45 \%$ of 82 begging bouts; anestrous female beggars in $48 \%$ of 139 begging bouts (Watts and Mitani, 2002a). Similarly, at Gombe, there was no statistically significant association between female reproductive state and the probability of active sharing, passive sharing or the amount of meat a female obtained $(\mathrm{N}=217$ begging bouts, 20 females, 8 adult males, Gilby, 2006). 
In this study, we identified 86 instances in 260 successful hunts between 1990 and 2006 at Kanyawara in which an adult female was observed in proximity to an unrelated adult male (neither son nor maternal brother) who was eating meat. We found that 5 different estrous females obtained meat in $7(41.2 \%)$ of 17 of these occasions (from 4 different males), while 11 anestrous females had 43.5\% success (30/69 with 11 different males). Again, this difference was not statistically significant (GEE logistic regression, $\chi^{2}{ }_{1}=0.03, \mathrm{P}=0.86$, repeated measure $=$ possessor/beggar $)$, further corroborating the results from Gombe and Ngogo.

Thus the only analyses that have taken into account the rate at which females approached male meat possessors reach the same conclusion: male chimpanzees do not take the sexual state of female beggars into account when making sharing decisions. Whether there are any circumstances under which males do respond to a female's sexual state by being more generous with meat is unknown.

Prediction 3: Males share preferentially with particularly fecund females.

There is growing evidence that chimpanzee mating behavior is sensitive to a female's probability of conception. Most notably, males solicit more copulations, and invest more in mate guarding, intersexual competition and sexual coercion when a female is most likely to conceive (Muller et al., 2007; Emery Thompson and Wrangham, 2008b). Highranking males are typically responsible for the majority of a female's copulations when conception risk is highest, such as during the peri-ovulatory period (POP) (Nishida, 1997; Emery Thompson and Wrangham, 2008b). Males at Kanyawara also prefer older, parous 
females as mating partners (Muller et al., 2006), and direct more sexual coercion toward them (Muller et al., 2007). As a result, it is possible that by simply classifying females as "estrous" or "anestrous", hence including many 'low-fecundity' females in our sharing analyses, we masked an important effect. Therefore, we tested whether males preferentially shared with 'high-fecundity’ females.

Over 16 years at Kanyawara, during which 520 meat-eating bouts were observed, an estrous female approached an unrelated male meat possessor on only 17 occasions. Estrous parous females obtained meat in $5 / 8$ of these begging bouts, all with the same male. Estrous nulliparous females obtained meat in 2/9 begging bouts with 5 different males. These data show no significant difference (GEE logistic regression, $\chi^{2}{ }_{1}=2.70, \mathrm{P}=$ 0.10 , repeated measure $=$ possessor/beggar. The small sample size serves to highlight the rarity of meat-for-sex opportunities at Kanyawara.

Between 1995 and 2005 at Gombe, our new analyses show that swollen females with known parity begged from focal males on 65 occasions (combining long-term data and the Gilby dataset). Parous females $(\mathrm{N}=9)$ obtained meat in $72 \%$ of 44 bouts, while nulliparous females $(\mathrm{N}=10)$ obtained meat in $43 \%$ of 21 bouts, a difference that approached statistical significance (GEE logistic regression, $\chi^{2}{ }_{1}=3.06, \mathrm{P}=0.08$, repeated measure $=$ possessor/beggar, Figure $2 \mathrm{~A}$ )

To account for the possibility that this trend could be independent of sexual state, we examined whether parity also affected sharing with anestrous females. This was indeed the case. At Gombe, anestrous parous beggars were significantly more likely to obtain meat ( $60 \%$ of 62 begging bouts) than anestrous nulliparous beggars ( $30 \%$ of 7 
begging bouts, GEE logistic regression, $\chi^{2}{ }_{1}=4.41, \mathrm{P}=0.04$, repeated measure $=$ possessor/beggar, Figure 2B). The same trend existed at Kanyawara, but was not statistically significant (GEE logistic regression, $\chi^{2}{ }_{1}=2.99, \mathrm{P}=0.08$, repeated measure $=$ possessor/beggar). One likely explanation for this pattern is that parous females (which tend to be older and higher-ranking (Kahlenberg et al., 2008)) may beg for meat more persistently than nulliparous females (regardless of sexual state) thus increasing their chances of obtaining meat.

Due to the small number of begging bouts $(\mathrm{N}=5)$ we were unable to test whether males at Kanyawara preferentially shared with females in POP. At Gombe however, we identified 70 instances in the long-term and Gilby datasets in which estrous females begged from focal males. In 51 of these bouts there were sufficient data to determine whether the female was in POP (between 2 and 7 days prior to detumescence: Deschner et al., 2003; Emery Thompson, 2005; Emery Thompson and Wrangham, 2008b) with high confidence. Females in POP were equally likely to obtain meat as estrous females outside of POP (GEE logistic regression, $\chi^{2}{ }_{1}=0.20, \mathrm{P}=0.65$, repeated measure $=$ possessor/beggar).

In sum, we found no evidence that males at Kanyawara and Gombe were more likely to share meat with estrous females with a high probability of conception (Table 1).

Prediction 4: Sharing meat is correlated with a male's short-term mating success.

The meat-for-sex hypothesis predicts that sharing with a sexually receptive female should be closely associated with copulation (Gilby, 2006), and in turn, mating rates during or 
closely following meat-eating bouts should be higher when sharing occurred than when it did not (Gilby, 2006; Mitani and Watts, 2001). We cannot test this prediction with much statistical power since the rate of copulations during meat-eating is low. Thus at Gombe, only $26(0.6 \%)$ of 4401 copulations recorded between 1995 and 2005 occurred during a meat-eating bout. Likewise at Kanyawara, only 6 matings $(0.1 \%)$ of the 4576 that were observed between 1996 and 2006 occurred when the copulating male possessed meat. However the available data do not support the hypothesis.

Stanford (1998) describes 5 instances in which a male withheld meat from a female until she mated with him. Additionally, mating occurred after $33 \%$ of successful hunts at which swollen females were present (Stanford, 1998). However, there was no evidence that the copulation rate was higher than expected. Furthermore, it was not reported whether the females who mated were those who received meat.

More recent data are contrary to the prediction that mating frequency is positively affected by sharing. At Ngogo, mating occurred in $43 \%$ of 37 sharing episodes with swollen females, a probability that was not statistically different from 0.5 (Watts and Mitani, 2002a). At Gombe, among begging bouts by swollen females, mating occurred in $35 \%$ of 23 bouts in which sharing occurred vs. $15 \%$ of 13 bouts without sharing (Gilby, 2006). While these data suggest that there might be a positive short-term effect of sharing on mating, the difference was not statistically significant after controlling for repeated observations of dyads $(\mathrm{P}=0.2)$. To examine this question further, we identified all instances (between 1995 and 2005) at Gombe $(\mathrm{N}=24)$ when a focal swollen female received meat from a male, and asked whether the male was more likely to mate with that 
female after sharing occurred than before. We limited our analysis to all instances in which both the female and the male were present in the same party for 3 hours before and 3 hours after sharing. Contrary to the prediction, the male meat donor was equally likely to mate with the female within the 3-hour period after sharing $(\mathrm{N}=4)$ as he was in the 3hour period before sharing $(\mathrm{N}=3)$ (Sign test, $\mathrm{P} \approx 1)$. On most $(10 / 17)$ occasions, no mating was observed either before or after sharing. Similarly, at Kanyawara (1990-2006), we recorded only 7 instances of sharing with a swollen female when both the male and female were present in the party for 3 hours before and 3 hours after sharing. Mating occurred on only two of these occasions - once immediately before sharing, and once immediately following sharing.

Thus data from Gombe, Ngogo and Kanyawara do not support the prediction that short-term male mating success is correlated with sharing (Table 1).

\section{Discussion}

Based on our review of meat-sharing and sexual behavior in chimpanzees, the widelycited hypothesis that male chimpanzees exchange meat with females to increase their short-term mating success is not supported. We challenge the fundamental assumptions of the hypothesis in light of existing models of exchange in mating markets. We note that female chimpanzees rarely require material incentives to mate, and that amid the competitive mating system of chimpanzees, the potential effects of such incentives on the reproductive success of either partner are insufficient to drive the evolution of meat sharing, particularly at the low rates reported from East African sites. 
Our review challenges in two ways the evidence that has been cited in favor of the meat-for-sex hypothesis . First, we note that support for the hypothesis has only ever come from a single statistically significant result (Stanford et al., 1994). Second, that result addressed hunting interest, rather than hunting behavior, and it did not consistently distinguish females that were motivated to copulated from those that were not.

Our statistical tests of four key predictions of the meat-for-sex hypothesis lead to consistent results. Collectively, these studies reveal that 1) the presence of sexually receptive females does not increase hunting probability; 2) males do not share preferentially with sexually receptive females; 3) males do not share preferentially with particularly fecund females; and 4) sharing with females does not increase a male's shortterm probability of mating. Our studies included two attempts to replicate early claims in favor of the meat-for-sex hypothesis, both of which failed.

If not for sex, then why do male chimpanzees share meat with females? We suggest that males share with females for the same reasons that they share with other males. Several studies have suggested that possessors share meat as a means of avoiding the costs associated with defending meat against persistent beggars (Wrangham, 1975; Stevens and Stephens, 2002; Stevens 2004). Indeed, Gilby (2006) showed that male

11/15/09 5:18 PM Given Brian W's observations of the Hadza. Maybe we do not want to suggest that human meatsharing is like chimpanzee meatsharing. chimpanzees at Gombe were more likely to share with females (and males) that were most persistent in their efforts to obtain meat. However it is also possible that males share with females in return for grooming or to reinforce a social bond, as can be the case with males (Mitani, 2006; but see Gilby, 2006). While some studies have demonstrated a 
reciprocal sharing pattern among males (reviewed in Muller and Mitani, 2005), it remains to be seen whether such sharing is due to a hidden third variable, such as harassment.

The meat-for-sex hypothesis was originally proposed to describe exchanges that would increase a male's immediate mating success (Stanford 1996). On the basis of all available evidence, we conclude that the meat-for-sex hypothesis must be rejected. We look forward to further tests to find out whether it applies in any circumstances to chimpanzees.

Whether males share meat with females as part of a long-term mating strategy remains a different and intriguing possibility. For example, chimpanzees occasionally form sexual consortships, in which a male and female travel together near the edge of the community range, actively avoiding other chimpanzees (Tutin, 1979). Mating is exclusive during these consortships, which may last weeks or months. While males sometimes succeed in forcing a female into consorting (Goodall, 1986), female cooperation promotes a successful consortship. At any point she could vocalize and alert the rest of the community to their location. In theory, males could use donations of meat to encourage female participation into future consortships.

This idea has been hinted at by Tutin (1979), who showed that Gombe males who frequently shared meat with females had high consortship rates. Unfortunately Tutin did not report whether these males had a relatively high tendency to share, or whether they were simply the most frequent meat possessors. Furthermore, Tutin (1979) did not show whether sharing with a particular female increased a male's chances of consorting with that female. A recent study at Bossou, Guinea, found that the beta male shared papaya 
with a frequent consort partner (Hockings et al., 2007), but there was no evidence that sharing and consorting were causally linked.

The strongest evidence supporting the notion that male chimpanzees use meat as part of a long-term mating strategy comes from a recent study at Taï. After controlling for several potentially confounding factors, including grooming rates, dominance rank, association patterns and begging frequency, Gomes and Boesch (2009) found that cycling females mated more often with males who shared meat with them at least once during a 22 month period than with males who never shared meat with them. This pattern remained significant after excluding all sharing with estrous females, suggesting that males were exchanging meat for sex on a long-term basis. It is striking because Gomes and Boesch (2009) found no evidence for short-term exchanges of meat-for-sex, nor did they find any correlation between the amount of meat shared (or the frequency of sharing) and the number of matings within the dyad. The study design did not allow testing of a predictable temporal link between sharing and copulation (i.e., whether sharing tended to occur prior to mating, or subsequently).

Gomes and Boesch's (2009) study raises important questions. First, if females do indeed value meat as a mating incentive, why would sharing predict long-term, but not short-term, mating frequency (see prediction 4, above)? Second, why was there no correlation between the amount of meat obtained by females and the number of times she copulated with the male? Third, could the long-term correlation between sharing and mating be due to the males who were skilled at getting meat (and were willing to share it) also being generally preferred sexual partners (for reasons unconcerned with meat- 
sharing). Finally, what proportion of meat sharing events at Taï can be explained by longterm meat-for-sex exchanges? Answers to such questions will indicate whether chimpanzees can maintain a longterm exchange of meat for sex, even in the absence of any short-term exchanges.

While the data from other study sites are sparse, the Taï result does not seem to be generalizable to other chimpanzee populations. At Ngogo, a given male was equally likely to mate with a female during sexual cycles in which he shared with her as during those in which he did not $(\mathrm{N}=12)$ (Mitani and Watts, 2001). Similarly, at Burgers' zoo (Arnhem, The Netherlands), males neither copulated more (Hemelrijk et al., 1992) nor sired more offspring (Hemelrijk et al., 1999) with those females with whom they most frequently shared food. It is possible therefore, that chimpanzee social dynamics are different in Taï from elsewhere. For example the rate of meat transfers observed at Taï (262 male-female meat transfers in 22 months (Gomes and Boesch, 2009)) was much greater than at the East African sites (e.g. Ngogo: 103 male-female meat transfers in 37 months (Watts and Mitani, 2002)), while the rate of copulations observed was much lower (0.144 copulations/hour (Gomes and Boesch, 2009), c.f. Ngogo: 3.53 copulations/ hour (Watts, 2007). These points suggest a different mating dynamic that may confer more agency to females at Taï.

Such inter-site variation raises the possibility that even short-term meat-for-sex exchanges may one day be found. They have not been found yet in chimpanzees, however. 


\section{Conclusions}

The notion that chimpanzees trade meat for sex has been frequently cited by anthropologists seeking to understand the evolutionary roots of human behavior. Food sharing is commonly heralded as an important milestone in human evolutionary history (Isaac, 1978), linked with such quintessential human traits as central place foraging, large, metabolically expensive brains (Aiello and Wheeler, 1995) and even the concepts of fairness, equity and punishment (Fehr and Schmidt, 1999; Gintis, 2000). Arguably, one of the most important putative consequences of food sharing for human evolution was the development of the sexual division of labor and pair bonds. Males concentrated their foraging efforts on hunting game, a high-quality, high-variance food source, while females collected low-quality, low-variance foods such as roots and tubers. Sharing allowed both sexes to have a high quality diet (i.e. more meat) while minimizing starvation risk. This scenario would have created mating competition for the most successful hunters, who could advertise their prowess by sharing meat widely and exchanging meat for sex, thus providing the foundation for pair bonds. While meat-forsex anecdotes in chimpanzees are often used as evidence for the evolutionary origin of these exchanges, the link between food-sharing, pair bonding and the derived nature of the hominin sexual division of labor, would actually be made more tenuous if our promiscuously-mating ancestors conducted similar exchanges of meat for sex. However we conclude that such scenarios are inappropriate. Instead, we find that meat transfers in chimpanzees are rarely sexually motivated. Short-term sexual bartering in humans appears to be a unique and derived human trait. 
Table 1. Summary of the conclusions of published studies that statistically tested the predictions of the meat-for-sex hypothesis, arranged by site and chronology. Blanks indicate that a given prediction was not tested. Each study is discussed in detail in the text. 'Sampling unit' indicates the smallest unit of analysis in a given study. Analyses focusing on events (e.g. bouts or encounters) are generally considered to be most informative. 'Level of analysis' indicates whether data analysis was conducted at the focal, dyad or group level. Group-level analyses often do not allow for appropriate tests of the predictions. There is considerable evidence against short-term meat-for-sex exchanges.

IAN - I THINK WE OUGHT TO PUT AN ASTERISK BY CRAIG'S RESULT, SAYING THAT IT APPLIED TO HUNTING INTEREST, NOT TO HUNTING (and note the estrous female problem). 


\begin{tabular}{|c|c|c|c|c|c|c|c|c|c|c|}
\hline \multicolumn{4}{|c|}{ Study details } & \multicolumn{7}{|c|}{ Predictions } \\
\hline \multirow[t]{2}{*}{ Site } & \multirow[t]{2}{*}{ Study } & \multirow[t]{2}{*}{\begin{tabular}{c|} 
Sampling \\
unit
\end{tabular}} & \multirow[t]{2}{*}{$\begin{array}{l}\text { Level of } \\
\text { analysis }\end{array}$} & \multirow{2}{*}{$\begin{array}{c}\text { Predictin 1: } \\
\text { Huntig ra re } \\
\text { likely when } \\
\text { estrous } \\
\text { females } \\
\text { present }\end{array}$} & \multicolumn{3}{|c|}{$\begin{array}{c}\text { Predictin 2: Preferentid } \\
\text { sharing with estrous } \\
\text { females }\end{array}$} & \multicolumn{2}{|c|}{$\begin{array}{c}\text { Prediction 3: Share with } \\
\text { partid a ly fec und fera I es }\end{array}$} & \multirow{2}{*}{$\begin{array}{r}\text { Predi } \\
\text { Sharing } \\
\text { with } \mathrm{m} \\
\text { term } \\
\text { su }\end{array}$} \\
\hline & & & & & $\begin{array}{c}\text { All } \\
\text { sharing }\end{array}$ & $\begin{array}{l}\text { Actie } \\
\text { sharing }\end{array}$ & $\begin{array}{l}\text { Amount } \\
\text { shared }\end{array}$ & Parous & POP & \\
\hline \multirow{4}{*}{ Gombe } & \begin{tabular}{|c} 
Stanford et al. \\
1994
\end{tabular} & $\begin{array}{c}\text { Prey } \\
\text { encoounter }\end{array}$ & $\begin{array}{l}\text { Group } \\
\text { wroum }\end{array}$ & YES & & & & & & \\
\hline & Gilby et al. 2006 & $\begin{array}{c}\text { Prey } \\
\text { encounter }\end{array}$ & Group/Focal & No & & & & & & \\
\hline & Gilby 2006 & $\begin{array}{l}\text { Begging bout } \\
\text { Sharing bout }\end{array}$ & $\begin{array}{l}\text { Dyad } \\
\text { Dyad }\end{array}$ & & No & No & No & & & \\
\hline & This study & \begin{tabular}{|l|} 
Begging bout \\
Sharing bout
\end{tabular} & $\begin{array}{l}\text { Dyad } \\
\text { Dyad }\end{array}$ & & & & & No & No & \\
\hline \multirow{2}{*}{ Kanyawara } & Gilby et al. 2008 & $\begin{array}{c}\text { Prey } \\
\text { encounter }\end{array}$ & Focal & No & No & & & & & \\
\hline & This study & Begging bout & Dyad & & & & & No & & \\
\hline \multirow[b]{2}{*}{ Ngogo } & $\begin{array}{l}\text { Mitani and } \\
\text { Watt p01 } \\
\text { W01 }\end{array}$ & $\begin{array}{c}\text { Prey } \\
\text { encounter }\end{array}$ & Group & NO & & & & & & \\
\hline & $\begin{array}{l}\text { Watt and } \\
\text { Mitani 2002a }\end{array}$ & $\begin{array}{l}\text { Begging bout } \\
\text { Sharing bout }\end{array}$ & Dyad & & No & & & & & \\
\hline Taï & $\begin{array}{l}\text { Gomes and } \\
\text { Boesch } 2009\end{array}$ & Male & Group & & TREND & & & & & \\
\hline
\end{tabular}




\section{Figure legends}

Figure 1. Probability of hunting vs. number of adult male and sexually receptive female chimpanzees in a party that encounters red colobus monkeys. From Gilby et al. (2006). Regression lines are from a logistic regression of 25 years of data from Gombe. Error bars represent $95 \%$ confidence intervals. At all party sizes, the presence of a sexually receptive female lowered the odds that at least one male hunted.

11/15/09 5:19 PM

It would be interesting to repea this analysis separately for impact and non-mpact hunters. Not now though!
Figure 2. Probability of sharing vs. parity and sexual state for A) swollen female beggars and B) non-swollen female beggars. Error bars represent 95\% confidence intervals from the logistic regressions described in the text. There was a non-significant tendency for males to share more often with parous swollen females than with nulliparous swollen females (A). However, this trend was likely to be due to a general effect of parity rather than sexual state, because males were significantly more likely to share with parous nonswollen females than with nulliparous non-swollen females (B). These results indicate that males did not share preferentially with parous females in order to increase the chances of an immediate copulation with a particularly fecund female. 
Figures

Figure 1.

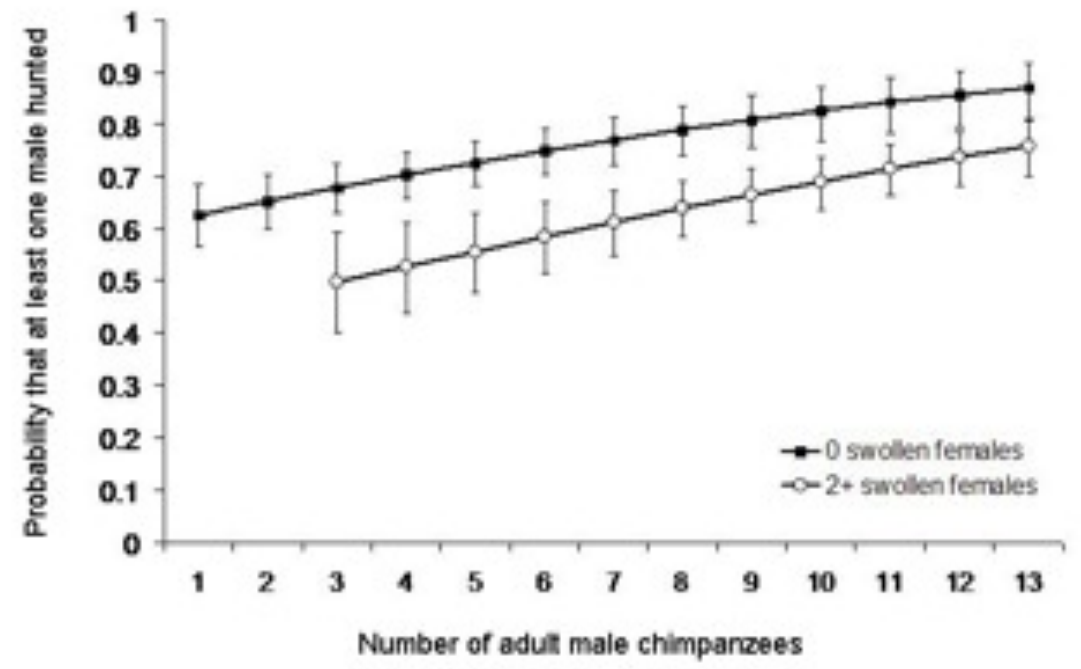


Figure 2.
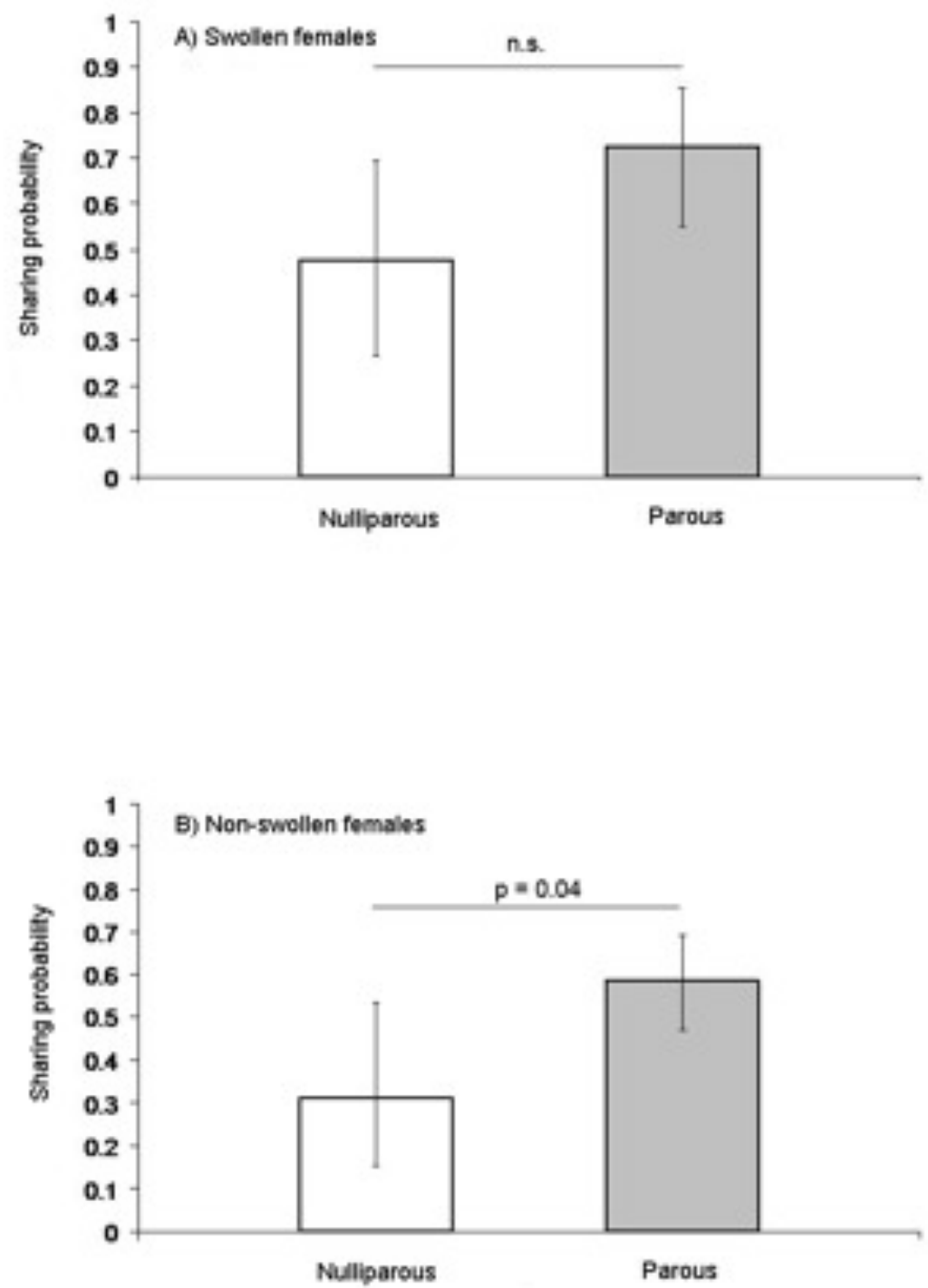


\section{Acknowledgements}

Long-term research at Kanyawara was supported by funding from NSF Grant 0416125 to

R. Wrangham. We thank the Uganda National Council for Science and Technology, the Uganda Wildlife Authority, and the Makerere University Biological Field Station for permission to conduct research within Kibale National Park. This project would not have been possible without the hard work and dedication of the field research team, especially Francis Mugurusi, Christopher Muruuli, Peter Tuhairwe, Christopher Katongole, and the late Donor Muhangyi and John Barwogeza. Similarly, field managers Michael Wilson, Martin Muller, Katherin Pieta, Carole Hooven, Kimberly Duffy, Alain Houle and Emily Otali were essential to the success of the project.

Research at Gombe is funded by the Jane Goodall Institute. We thank Tanzania National Parks, the Tanzania Wildlife Research Institute, and the Tanzanian Commission for Science and Technology for granting us permission to work in Gombe National Park. We are deeply indebted to the Gombe Stream Research Center staff for maintaining data collection, and Drs. Jane Goodall and Anne Pusey for granting us permission to work with the long-term dataset. Digitization of the long-term data at the Jane Goodall Institute's Center for Primate Studies, under the direction of Anne Pusey, was supported by grants from the National Science Foundation (DBS-9021946, SBR-9319909, BCS-0452315), the University of Minnesota, the Harris Steel Group, the Windibrow Foundation, the Carnegie Corporation and Minnesota Base Camp. Data analysis for this project was funded by a grant from the National Science Foundation (NSF \# IIS- 
0431141). Many thanks to Esther Collins for translation and Joann Schumacher-Stankey for extracting mating data.

Fieldwork by I. Gilby was supported by the L.S.B. Leakey Foundation, the Animal Behaviour Society, Sigma Xi, the Explorers Club, the Dayton and Wilkie Natural History Funds, the University of Minnesota's Grants for Research Abroad Program, and the Department of Ecology, Evolution and Behavior at the University of Minnesota.

Many thanks to Anne Pusey for comments on earlier versions of this manuscript.

\section{References}

Aiello, L.C., Wheeler, P., 1995. The expensive tissue hypothesis: the brain and digestive system in human and primate evolution. Curr Anthropol. 36, 199-221.

Arnqvist, G. \& Nilsson, T., 2000. The evolution of polyandry: Multiple mating and female fitness in insects. Anim Behav. 60, 145-164.

Brown, G. R., Almond, R. E. A., van Bergen, Y. 2004. Begging, stealing and offering: food transfer in nonhuman primates. Adv Stud Behav. 34, 265-296.

Bird, R., 1999. Cooperation and conflict: the behavioral ecology of the sexual division of labor. Evol Anthropol. 8, 65-75.

Blurton Jones, N.G., 1984. A selfish origin for human food sharing: tolerated theft. Ethol Sociobiol. 5, 1-3.

Blurton Jones, N.G., 1987. Tolerated theft: suggestions about the ecology and evolution of sharing, hoarding and scrounging. Soc Sci Inform. 26, 31-54. 
Boesch, C., 1994. Chimpanzees-red colobus monkeys: a predator-prey system. Anim Behav. 47, 1135-1148.

Boesch, C., Boesch, H., 1989. Hunting behavior of wild chimpanzees in the Taï National Park. Am J Phys Anthropol. 78, 547-573.

Boesch, C., Boesch-Achermann, H., 2000. The Chimpanzees of the Taï Forest. Behavioural Ecology and Evolution. Oxford University Press, Oxford.

Boesch, C., Kohou, G., Nene, H., Vigilant, L., 2006. Male competition and paternity in wild chimpanzees of the Taï forest. Am J Phys Anthropol. 130, 103-115.

Bunn, H.T., 2007. Meat made us human. In: Ungar, P. (Ed.) Evolution of the human diet. Oxford University Press, Oxford, pp 191-211.

Clutton-Brock, T.H., Harvey, P.H., 1976. Evolutionary rules and primate societies. In: Bateson, P.P.G., Hinde, R.A. (Eds.), Growing points in ethology. Cambridge University Press, Cambridge, pp 195-237.

Constable, J.L., Ashley, M.V., Goodall, J., Pusey, A.E., 2001. Noninvasive paternity assignment in Gombe chimpanzees. Mol Ecol. 10, 1279-1300.

Deschner, T., Boesch, C., 2007. Can the patterns of sexual swelling cycles in female Taï chimpanzees be explained by the "cost-of-sexual attraction" hypothesis? Int J Primatol. 28, 389-406.

Deschner, T., Heistermann, M., Hodges, K., Boesch, C., 2003. Timing and probability of ovulation in relation to sex skin swelling in wild West African chimpanzees, Pan troglodytes verus. Anim Behav. 66, 551-560. 
Dixson, A.F., Mundy, N.J., 1994. Sexual behavior, sexual swelling, and penile evolution in chimpanzees (Pan troglodytes). Arch Sex Behav. 23, 267-280.

Duffy, K.G., Wrangham, R.W., Silk, J.B., 2007. The price of power: male chimpanzees exchange political support for mating opportunities. Curr Biol. 17, R586 - R587.

Emery Thompson, M., 2005. Reproductive endocrinology of wild female chimpanzees (Pan troglodytes schweinfurthii): methodological considerations and the role of hormones in sex and conception. Am J Primatol. 67, 137-158.

Emery Thompson, M., Jones, J.H., Pusey, A.E., Brewer Marsden, S., Goodall, J., Marsden, D., Matsuzawa, T., Nishida, T., Reynolds, V., Sugiyama, Y., Wrangham, R.W., 2007a. Aging and fertility patterns in wild chimpanzees provide insights into the evolution of menopause. Curr Biol. 17, 2150-2156.

Emery Thompson, M., Kahlenberg, S.M., Gilby, I.C., Wrangham, R.W., 2007b. Core area quality is associated with variance in reproductive success among female chimpanzees at Kibale National Park. Anim Behav. 73, 501-512.

Emery Thompson, M., Wrangham, R.W., 2008a. Diet and reproductive function in wild female chimpanzees (Pan troglodytes schweinfurthii) at Kibale National Park, Uganda. Am J Phys Anthropol. 135, 171-181.

Emery Thompson, M., Wrangham, R.W., 2008b. Male mating interest varies with female fecundity in Pan troglodytes schweinfurthii of Kanyawara, Kibale National Park. Int J Primatol. 29, 885-905.

Fedorka, K. M. \& Mousseau, T. A., 2002. Nuptial gifts and the evolution of male body size. Evolution. 56, 590-596. 
Fehr, E., Schmidt, K.M., 1999. A theory of fairness, competition and cooperation. Q J Econ. 114, 817-868.

Gilby, I.C. 2004. Hunting and meat sharing among the chimpanzees of Gombe National Park, Tanzania. PhD thesis, University of Minnesota.

Gilby, I.C., 2006. Meat sharing among the Gombe chimpanzees: harassment and reciprocal exchange. Anim Behav. 71, 953-963.

Gilby, I.C., Eberly, L.E., Pintea, L., Pusey, A.E., 2006. Ecological and social influences on the hunting behaviour of wild chimpanzees (Pan troglodytes schweinfurthii). Anim Behav. 72, 169-180.

Gilby, I.C., Eberly, L.E., Wrangham, R.W., 2008. Economic profitability of social predation among wild chimpanzees: individual variation promotes cooperation. Anim Behav. 75, 351-360.

Gilby, I.C., Wrangham, R.W., 2008. Association patterns among wild chimpanzees (Pan troglodytes schweinfurthii) reflect sex differences in cooperation. Behav Ecol Sociobiol. 62, 1831-1842.

Gintis, H., 2000. Strong reciprocity and human sociality. J Theor Biol. 206, 169-179.

Gomes, C. M. and Boesch, C., 2009. Wild chimpanzees exchange meat for sex on a longterm basis. PLoS ONE 4: e5116.

Goodall, J., 1986. The chimpanzees of Gombe: patterns of behavior. Harvard University Press, Cambridge, MA.

Gregor, T., 1985. Anxious pleasures: the sexual lives of an Amazonian people. University of Chicago Press, Chicago. 
Gwynne, D.T., 2008. Sexual conflict over nuptial gifts in insects. Annu. Rev. Entomol. $53,83-101$.

Harcourt, A.H., 1995. Sexual selection and sperm competition in primates: what are male genitalia good for? Evol Anthropol. 4, 121-129.

Hasegawa, T., Hiraiwa-Hasegawa, M., 1990. Sperm competition and mating behavior. In: Nishida, T. (Ed.) The chimpanzees of the Mahale Mountains: sexual and life history strategies. University of Tokyo Press, Tokyo, pp 115-132.

Hawkes, K., Bird, R. B. 2002. Showing off, handicap signaling, and the evolution of men's work. Evol Anthropol. 11, 58-67.

Hemelrijk, C.K., Meier, C., Martin, R.D. 1999. 'Friendship' for fitness in chimpanzees? Anim Behav. 58, 1223-1229.

Hemelrijk, C.K., van Laere, G.J., van Hooff, J.A.R.A.M., 1992. Sexual exchange relationships in captive chimpanzees? Behav Ecol Sociobiol. 30, 269-275.

Hockings, K.J., Humle, T., Anderson, J.R., Biro, D., Sousa, C., Ohashi, G., Matsuzawa, T., 2007. Chimpanzees share forbidden fruit. PLoS ONE. 2, e886.

Holmberg, A.R., 1969. Nomads of the Long Bow. The Siriono of Eastern Bolivia. Natural History Press, Garden City, NY.

Hrdy, S.B., 1979. Infanticide among animals - review, classification, and examination of the implications for the reproductive strategies of remales. Ethol Sociobiol. 1, $13-40$. 
Inoue, E., Inoue-Murayama, M., Vigilant, L., Takenaka, O., Nishida, T., 2008.

Relatedness in wild chimpanzees: influence of paternity, male philopatry, and demographic factors. Am J Phys Anthropol. 137, 256-262.

Isaac, G., 1978. The food-sharing behavior of protohuman hominoids. Sci Am. 238, 90-108.

Kahlenberg, S.M., Emery Thompson, M., Wrangham, R.W., 2008. Female competition over core areas in Pan troglodytes schweinfurthii, Kibale National Park, Uganda. Int J Primatol. 29, 931-947.

Lovejoy, C. O. 2009. Reexamining human origins in light of Ardipithecus ramidus. Science $326,74 \mathrm{e} 71-74 \mathrm{e} 78$.

Matsumoto-Oda, A., 1999. Female choice in the opportunistic mating of wild chimpanzees (Pan troglodytes schweinfurthii) at Mahale. Behav Ecol Sociobiol. $46,258-266$.

McGrew, W.C., 1992. Chimpanzee material culture. Cambridge University Press, Cambridge.

Milton, K., 1985. Mating patterns of woolly spider monkeys, Brachyteles arachnoides implications for female choice. Behav Ecol Sociobiol. 17, 53-59.

Milton, K., 2003a. The critical role played by animal source foods in human (Homo) evolution. J Nutr. 133, 3886S-3892S.

Milton, K., 2003b. Micronutritient intakes of wild primates: are humans different? Comp Biochem Phys A. 136, 47-59. 
Mitani, J.C., 2006. Reciprocal exchange in chimpanzees and other primates. In: Kappeler, P.M., van Schaik, C.P. (Eds.), Cooperation in primates: mechanisms and evolution. Springer-Verlag, Heidelberg, pp 101-113.

Mitani, J.C., Watts, D.P., 1999. Demographic influences on the hunting behavior of chimpanzees. Am J Phys Anthropol. 109, 439-454.

Mitani, J.C., Watts, D.P., 2001. Why do chimpanzees hunt and share meat? Anim Behav. $61,915-924$.

Muller, M.N., Emery Thompson, M., Kahlenberg, S.M., Wrangham, R.W., In review. Male coercion constrains female choice in wild chimpanzees.

Muller, M.N., 2002. Agonistic relations among Kanyawara chimpanzees. In: Boesch, C., Hohmann, G., Marchant, L. (Eds.), Behavioural diversity in chimpanzees and bonobos. Cambridge University Press, Cambridge, pp 112-124.

Muller, M.N., Emery Thompson, M., Wrangham, R.W., 2006. Male chimpanzees prefer mating with old females. Curr Biol. 16, 2234-2238.

Muller, M.N., Kahlenberg, S.M., Emery Thompson, M., Wrangham, R.W., 2007. Male coercion and the costs of promiscuous mating for female chimpanzees. P Roy Soc Lond B Bio. 274, 1009-1014.

Muller, M.N., Kahlenberg, S.M., Wrangham, R.W., 2009. Male aggression and sexual coercion in chimpanzees. In: Muller, M.N., Wrangham, R.W. (Eds.), Sexual coercion in primates: an evolutionary perspective on male aggression against females. Harvard University Press, Cambridge, MA, pp 3-22. 
Muller, M.N., Mitani, J.C., 2005. Conflict and cooperation in wild chimpanzees. Adv Stud Behav. 35, 275-331.

Newton-Fisher, N.E., 2004. Hierarchy and social status in Budongo chimpanzees. Primates. 45, 81-87.

Newton-Fisher, N.E., Notman, H., Reynolds, V., 2002. Hunting of mammalian prey by Budongo Forest chimpanzees. Folia Primatol. 73, 281-283.

Newton-Fisher, N.E., Emery Thompson, M., Reynolds, V., Boesch, C. , Vigilant, L., In review. Paternity and social rank in wild chimpanzees (Pan troglodytes) from the Budongo Forest, Uganda.

Nishida, T., 1968. The social group of wild chimpanzees in the Mahali mountains. Primates. 9, 167-224.

Nishida, T., Hasegawa, T., Hayaki, H., Takahata, Y., Uehara, S., 1992. Meat-sharing as a coalition strategy by an alpha male chimpanzee? In: Nishida, T., McGrew, W.C., Marler, P., Pickford, M., de Waal, F.B.M. (Eds.), Topics in primatology. Vol. 1. human origins University of Tokyo Press, Tokyo, pp 159-174.

Nishida, T., 1997. Sexual behavior of adult male chimpanzees of the Mahale Mountains National Park, Tanzania. Primates. 38, 379-398.

Noë R, Hammerstein, P., 1994. Biological markets: supply and demand determine the effect of partner choice in cooperation, mutualism and mating. Behav Ecol Sociobiol. 35, 1-11.

Noë, R., Hammerstein, P., 1995. Biological markets. Trends Ecol Evol. 10, 336-339. 
Noë, R., van Schaik, C.P. \& van Hooff, J.A.R.A.M., 1991. The market effect: an explanation for pay-off asymmetries among collaborating animals. Ethology. 87, 97-118.

Pieta, K., 2008. Female mate preferences among chimpanzees (Pan troglodytes schweinfurthii) of Kanyawara, Kibale National Park. Int J Primatol. 29, 845-864.

Pollock D., 2002. Partible paternity and multiple maternity among the Kulina. In: Beckerman, S, and Valentine, P. (Eds.), Cultures of multiple fathers: the theory of practice of partible paternity in lowland South America. University Press of Florida, Gainesville, FL., pp 42-61.

Pusey, A.E., Oehlert, G.W., Williams, J.M., Goodall, J., 2005. Influence of ecological and social factors on body mass of wild chimpanzees. Int J Primatol. 26, 3-31.

Pusey, A.E., Williams, J.M., Goodall, J., 1997. The influence of dominance rank on the reproductive success of female chimpanzees. Science. 277, 828-831.

Radetsky, P., 1995. Gut thinking. Discover. 76-81.

Reynolds, V., 2005. The chimpanzees of the Budongo forest - ecology, behaviour, and conservation. Oxford University Press, Oxford.

Shlain, L. (2003). Sex, time and power: how women's sexuality shaped human evolution. Viking, New York, NY.

Small, M.F., 1988. Female primate sexual behavior and conception: are there really sperm to spare? Curr Anthropol. 29, 81-95.

Stanford, C., 1996. The hunting ecology of wild chimpanzees: implications for the evolutionary ecology of Pliocene hominids. Am Anthropol. 98, 96-113. 
Stanford, C.B., 1998. Chimpanzee and red colobus. Harvard University Press, Cambridge, MA.

Stanford, C.B., 2001. A comparison of social meat-foraging by chimpanzees and human foragers. In: Stanford, C.B., Bunn, H.T. (Eds.), Meat-eating and human evolution. Oxford University Press, Oxford, pp 122-140.

Stanford, C.B., Wallis, J., Mpongo, E., Goodall, J., 1994. Hunting decisions in wild chimpanzees. Behaviour. 131, 1-18.

Stevens, J.R., 2004. The selfish nature of generosity: harassment and food sharing in primates. Proc Roy Soc Lond B Biol. 271, 451-456.

Stevens, J.R., Stephens, D.W., 2002. Food sharing: a model of manipulation by harassment. Behav Ecol. 13, 393-400.

Stumpf, R.M., Boesch, C., 2005. Does promiscuous mating preclude female choice? female sexual strategies in chimpanzees (Pan troglodytes verus) of the Taï National Park, Cote d'Ivoire. Behav Ecol Sociobiol. 57, 511-524.

Stumpf, R.M., Boesch, C., 2006. The efficacy of female choice in chimpanzees of the Taï Forest, Cote d'Ivoire. Behav Ecol Sociobiol. 60, 749-765.

Takahata, Y., Hasegawa, T., Nishida, T., 1984. Chimpanzee predation in the Mahale Mountains from August 1979 to May 1982. Int J Primatol. 5, 213-233.

Teleki, G., 1973. The predatory behavior of wild chimpanzees. Bucknell University Press, Lewisburg, PA. 
Tennie, C., Gilby, I.C., Mundry, R., 2009. The meat-scrap hypothesis: small quantities of meat may promote cooperation in wild chimpanzees (Pan troglodytes). Behav Ecol Sociobiol. 63, 421-431.

Thornhill, R., 1984. Alternative female choice tactics in the scorpion fly Hylobittacus apicalis (Mecoptera) and their implications. Am Zool. 24, 367-383.

Trivers, R. L., 1971. The evolution of reciprocal altruism. Q Rev Biol._46, 35-57.

Tutin, C.E.G., 1979. Mating patterns and reproductive strategies in a community of wild chimpanzees (Pan troglodytes schweinfurthii). Behav Ecol Sociobiol. 6, 29-38.

Uehara, S., 1997. Predation on mammals by the chimpanzee (Pan troglodytes). Primates. $38,193-214$.

van Schaik, C.P., Hodges, J.K., Nunn, C.L., 2000. Paternity confusion and the ovarian cycles of female primates. In: van Schaik, C.P., Janson, C.H. (Eds.), Infanticide by males and its implications. Cambridge University Press, Cambridge, pp 361-387.

Yerkes, R.M. (1943). Chimpanzees: a laboratory colony. Yale University Press. New Haven, CT.

Wallis, J., 1982. Sexual behavior of captive chimpanzees (Pan troglodytes): pregnant versus cycling females. Am J Primatol. 3, 77-88.

Wallis, J., 1997. A survey of reproductive parameters in the free-ranging chimpanzees of Gombe National Park. J Reprod Fertil. 109, 297-307.

Watts, D.P., 1998. Coalitionary mate guarding by male chimpanzees at Ngogo, Kibale National Park, Uganda. Behav Ecol Sociobiol. 44, 43-55. 
Watts, D.P., 2007. Effects of male group size, parity, and cycle stage on female chimpanzee copulation rates at Ngogo, Kibale National Park, Uganda. Primates. 48, 222-231.

Watts, D.P., Mitani, J.C., 2002a. Hunting and meat sharing by chimpanzees at Ngogo, Kibale National Park, Uganda. In: Boesch, C., Hohmann, G., Marchant, L. (Eds.), Behavioural diversity in chimpanzees and bonobos. Cambridge University Press, Cambridge, pp 244-255.

Watts, D.P., Mitani, J.C., 2002b. Hunting behavior of chimpanzees at Ngogo, Kibale National Park, Uganda. Int J Primatol. 23, 1-28.

Williams, J.M., Pusey, A.E., Carlis, J.V., Farm, B.P., Goodall, J., 2002. Female competition and male territorial behaviour influence female chimpanzees' ranging patterns. Anim Behav. 63, 347-360.

Wrangham, R.W., 1975. The behavioural ecology of chimpanzees in Gombe National Park, Tanzania. Ph.D. dissertation, Cambridge University.

Wrangham, R.W., 2002. The cost of sexual attraction: is there a trade-off in female Pan between sex appeal and received coercion? In: Boesch, C., Hohmann, G., Marchant, L. (Eds.), Behavioural diversity in chimpanzees and bonobos. Cambridge University Press, Cambridge, pp 204-215.

Wrangham, R.W., Clark, A.P., Isabirye-Basuta, G., 1992. Female social relationships and social organization of Kibale forest chimpanzees. In: Nishida, T., McGrew, W.C., Marler, P., Pickford, M., de Waal, F.B.M. (Eds.), Topics in primatology. Vol. 1. human origins. Tokyo University Press, Tokyo, pp 81-98. 
Wrangham, R.W., Smuts, B., 1980. Sex differences in the behavioral ecology of chimpanzees in the Gombe National Park, Tanzania. J Reprod Fertil Supp. 28, 13-31.

Wroblewski, E.E., Murray, C.M., Keele, B.F., Schumacher-Stankey, J.C., Hahn, B.H., Pusey, A.E., 2009. Male dominance rank and reproductive success in chimpanzees, Pan troglodytes schweinfurthii. Anim Behav. 77, 873-885. 